\title{
Prevention of Pleural Adhesions Ising a Membrane Containing Polyeth- ylene Glycol in Rats
}

\section{Volkan Karacam ${ }^{1 凶}$, Ahmet Onen², Aydin Sanli², Duygu Gurel ${ }^{3}$, Aydanur Kargi ${ }^{3}$, Sami Karapolat ${ }^{4}$, Nezih Ozdemir²}

1. Department of Thoracic Surgery, State Hospital, Bilecik, Turkey

2. Department of Thoracic Surgery, Dokuz Eylul University, Izmir, Turkey

3. Department of Pathology, Dokuz Eylul University, Izmir, Turkey

4. Department of Thoracic Surgery, Duzce University, Duzce, Turkey

Corresponding author: Volkan Karacam MD., Department of Thoracic Surgery, State Hospital, Bilecik, Turkey. Phone: +90 (228) 21210 36; Fax: +90 (228) 21257 98; E-mail: volkan_karacam@yahoo.com

(C) Ivyspring International Publisher. This is an open-access article distributed under the terms of the Creative Commons License (http://creativecommons.org/ licenses/by-nc-nd/3.0/). Reproduction is permitted for personal, noncommercial use, provided that the article is in whole, unmodified, and properly cited.

Received: 2011.03.28; Accepted: 2011.05.31; Published: 2011.06.17

\begin{abstract}
Background: Recurrent thoracotomies regardless of the cause are not a rare occurrence. However, each thoracotomy results in adhesion to some extent. This adhesions increase morbidity and mortality presents a significant inconvenience for surgeons and prolongs the length of operations.

Objective: We investigated the efficacy of Prevadh ${ }^{\circledR}$, an anti-adhesion agent to prevent intrapleural adesions following thoracotomy in a rat model.

Methods: Twenty male adult Wistar Albino rats were divided into a sham group (Group A, $n=4$ ), a control group (Group B, $n=8$ ), and a study group (Group C, $n=8$ ). Only left thoracotomy was performed in Group A. Group B underwent left thoracotomy, induction of adhesion, and $1 \mathrm{ml}$ saline solution was administered to the thoracic cavity. However, in Group C underwent left thoracotomy, induction of adhesion, and Prevadh ${ }^{\circledR}$ was placed between the pleura and the lung. The rats were sacrificed on day 21, and adhesions were analyzed using both macroscopic and histopathological methods. The results were statistically analyzed. A value of $P<0.05$ was considered statistically significant.
\end{abstract}

Results: Mean lengths of adhesion differed statistically significantly among all three groups, while mean intensity of adhesion differed between Group A and Group B, and between Group B and Group C ( $P>0.05)$. There was also a statistically significant difference between Group A and Group C in mesothelium proliferation score $(P>0.05)$. No statistically significant differences were found among the groups in terms of pleural thickness, macrophage and mononuclear cell infiltration $(P>0.05)$.

Conclusions: Prevadh ${ }^{\circledR}$ was shown in a rat model to effectively prevent post-thoracotomy adhesions.

Key words: Thoracic Surgery; Thoracotomy; Tissue Adhesions; Polyethylene Glycols

\section{INTRODUCTION}

There are only a few studies on intrapleural adhesions following thoracotomy [1], whereas many clinical and empirical studies have been conducted to investigate adhesions that occur after abdominal 
surgeries [2,3]. This is because adhesions following abdominal surgery leads to serious complications, while it is even a desired effect in thoracic surgery, since adhesions that develop between visceral and parietal pleura's after thoracotomy provides a natural pleurodesis effect by preventing postoperative air leakages and pleural effusion. However, these adhesions may cause significant problems in recurrent thoracotomies.

Today, recurrent thoracotomies are being seen with increasing frequency particularly in metastatic lung cancer, unilateral metachronous lung cancer, and recurrent pneumothorax. More than tree resections in a single patient are not a rare condition $[4,5]$. Significant adhesions occur in these patients, especially behind the thoracotomy incision line. These scar tissues put surgeons in a difficult position, make it difficult to free the lung and to access to hilus, and causes bleeding and prolonged air leaks [6, 7]. This results increased operation times, morbidity and mortality.

Anti-adhesion barriers are rarely used in thoracic surgeries, and only a few experimental studies have been performed on this subject. Tanaka et al. have shown that adhesions may be avoided following thoracotomy by using a hyaluronate-based absorbable membran in rats [6]. Also, Getman et al. achieved the same effect by using haemostatic membrane [7].

The present study investigates the efficacy of Prevadh ${ }^{\circledR}$ (Tyco/Sofradim, Trevoux, French), which is an anti-adhesion barrier composed of collagen, polyethylene glycol and glycerol following thoracotomy in a rat model. The purpose of this experimental study is to determine the safety and efficacy of this substance before it is studied in clinical trials in humans.

\section{METHODS}

\section{Population}

A prospective, randomized, double-blinded, controlled, experimental study was conducted with 20 male adult Wistar albino rats from the same colony weighting 250-300 g. The rats were obtained from the Experimental Animals Laboratory of Dokuz Eylul University Faculty of Medicine. The purpose of using rats is easy availability, safety, and the high ratio of repeating the experiment.

\section{Design}

The rats were randomly divided into three groups: Group A: Sham $(n=4)$ and Group B: Control $(n=8)$, Group C: Study $(n=8)$. They were maintained under specific pathogen-free conditions to avoid infections and housed separately in a light-controlled room with a $12: 12 \mathrm{~h}$ light-dark cycle. The temperature $\left(22 \pm 0.5^{\circ} \mathrm{C}\right)$ and relative humidity $(65-70 \%)$ were kept constant. Standard laboratory rodent chow and water were available ad libitum. They were deprived of food for $12 \mathrm{~h}$ before the experiment but had free access to water.

All of the rats were anesthetized by administering ketamine hydrochloride (Ketalar, Pfizer, Turkey) $40 \mathrm{mg} / \mathrm{kg}$ and xylazine hydrochloride (Rompun, Bayer, Turkey) $4 \mathrm{mg} / \mathrm{kg}$ intraperitoneally. During the procedure, additional doses were administered if necessary. The rats were intubated with 16G plastic catheters. During intubation, the rats were administered $0.1 \mathrm{mg} / \mathrm{kg}$ intravenous vecuronium bromide as neuromuscular blocker and, throughout the operation, they received ventilation support in volume-control mode, which provided 90 respiration counts and a volume of $15-20 \mathrm{ml} / \mathrm{kg}$ per minute (Hugo Sacs, Rodent Ventilator, Germany). The body temperature was maintained at $37.0^{\circ} \mathrm{C}$ with a heat pad to prevent the effects of hypothermia and to maintain the stability of hemodynamic parameters. They were placed in right decubitus position, the operation site was disinfected, shaved, and particular attention was paid for asepsis and antisepsis during operation. Left posterolateral thoracotomy from the $4^{\text {th }}$ intercostal space was performed in all groups.

Only thoracotomy was performed in Group A. Group B underwent thoracotomy, induction of adhesion, and $1 \mathrm{ml}$ normal saline solution was administered to the thoracic cavity (Figure 1A). However, Group $C$ underwent thoracotomy, induction of adhesion, and Prevadh ${ }^{\circledR}$ sized $3 \times 3 \mathrm{~cm}$. was placed between the pleura and the lung (Figure 1B). All three groups were checked against bleeding, air leakage, and the layers were closed appropriately. The rats were extubated after they resumed spontaneous breathing, and were kept in separate cages. No antibiotics were administered during or after surgery. The rats received intramuscular morphine HCL $0.1 \mathrm{mg} / \mathrm{kg}$ in every 12 hours during the first 24 hours. The rats were sacrificed using ether at lethal doses on day 21, when wound healing was complete and anti-adhesion barrier was completely absorbed.

\section{Induction of intrapleural adhesion model}

Adhesion model was generated based on the model in the study by Tanaka et al., which was modified in this study [6]. The parietal pleura was scratched using spanch after the procedure described above. Later, visceral pleura was abraded with dry spanch first, followed by spanch wetted with $0.1 \mathrm{ml}$ iodine, avoiding air leakage and bleeding. 


\section{Macroscopic examination}

Recurrent thoracotomy was performed at the $8^{\text {th }}$ or $9^{\text {th }}$ intercostal space and intrapleural adhesions were analyzed macroscopically (Figure 1C and 1D). Adhesions were scored as shown below: A) Length of adhesion: The length of adhesion before the first thoracotomy incision (mm). B) Scoring of the intensity of adhesion between the parietal pleura and the lung: 1: No adhesion, 2: Loose: Which can be removed with blunt dissection, 3: Moderate: Some of which requires sharp dissection, 4: Severe: All of which requires sharp dissection.

\section{Microscopic examination}

The chest wall was removed en bloc with adhered lung. Following fixation with

Figure 1. Macroscopic images of the rats. A: Appearance of the visceral pleura after abrasion with dry and iodinated spanch. B: Placement of a $3 \times 3 \mathrm{~cm}$ anti-adhesion membrane (Prevadh $₫$ ) in the adhesion model-induced rat between the lung and parietal pleura. C: Recurrent thoracotomy of the Group B at the $9^{\text {th }}$ intercostal space after 21 days and image of the adhered lung and adhesions across the previous thoracotomy line. D: Image of the recurrent thoracotomy after 21 days in the Group C with anti-adhesion membrane installed. buffered formaldehyde $10 \%$ and decalcification with Planko-Rychlo solution, the chest wall was incised with $5 \mathrm{~mm}$ spaces such that the chest wall will position perpendicular to the ribs. Light microscopy was used for histopathological analysis of the Hematoxylin-Eosin stained sections (Figure 2A and 2B).
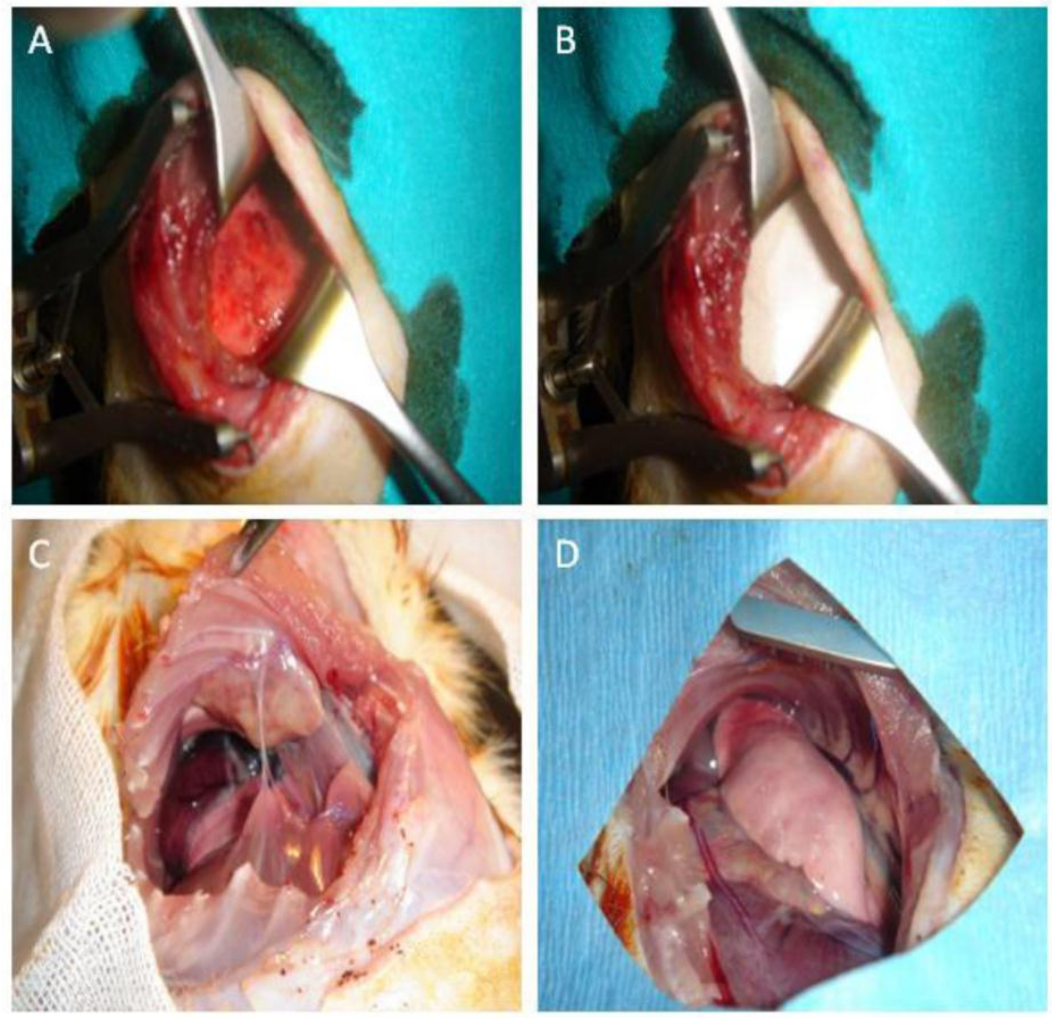
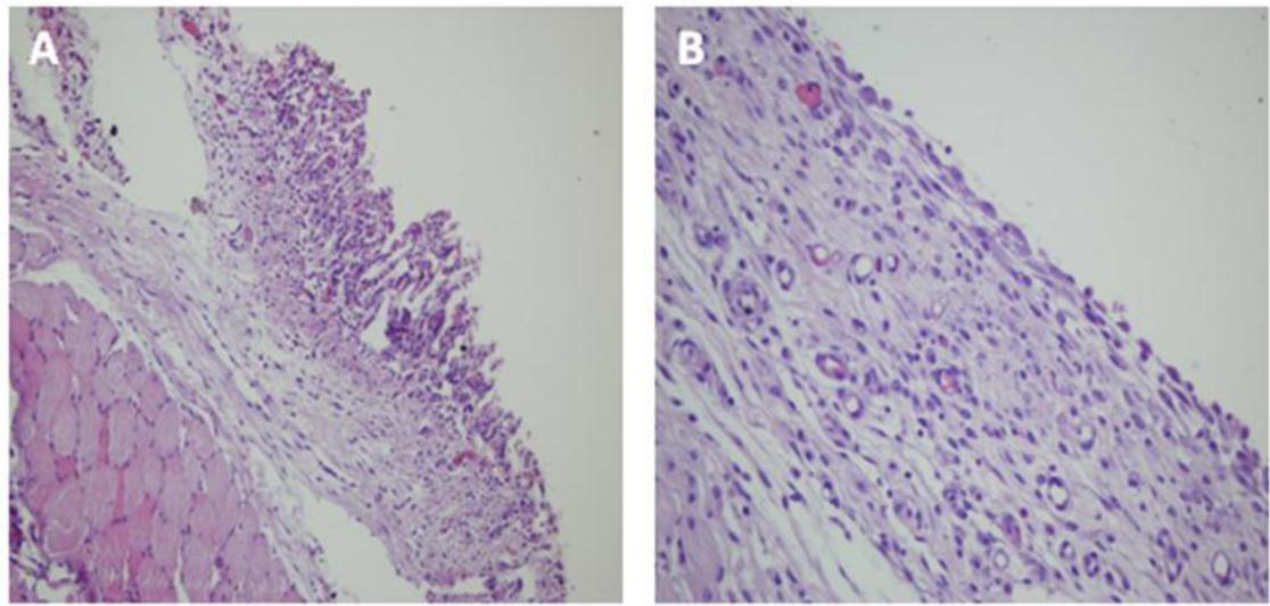

Figure 2. Microscopic images of the rats. A: Lung tissue adhered to the thoracotomy line in the Group B (Hematoxylin-Eosin $\times 40$ magnification). B: In the Group C, complete mesothelial regeneration and smooth pleural surface were determined (Hematoxylin-Eosin x200 magnification). 


\section{Assessment of changes in parietal pleura}

Scoring mesothelium cell proliferation: This variable demonstrates the integrity of the mesothelium tissue (x200 magnification). 1: Pleural surface is completely covered with mesothelium cells, 2: Fifty percent of pleural surface is covered with mesothelium cells, 3: Less than $50 \%$ of the pleural surface is covered with mesothelium cells, and 4: Absence of mesothelium tissue.

Infiltration score for mononuclear inflammatory cells (MICs): In the collagen layer under the adhered lung tissue or over the pleural surface (x400 magnification). 1: Mild: Almost no MIC, 2: Moderate: MIC count < 100, 3: Marked: MIC count > 100.

Infiltration score for macrophages in the collagen tissue (x400 magnification). 1: Mild: Almost no macrophages, 2: Moderate: Macrophage count < 100, 3: Marked: Macrophage count $>100$.

\section{Ethics}

The study was approved by a local ethics board of Dokuz Eylul University Faculty of Medicine, Animal Care and Use Committee. The rats were cared for in accordance with the Guide for the Care and Use of Laboratory Animals.

\section{Statistical analysis}

The results were recorded by the principal investigator and analyzed statistically upon completion of the study. The statistical analysis was performed with SPSS software, version 15 (SPSS, Inc., Chicago, IL). Clinical data were expressed as the median \pm the standard error of mean (minimum-maximum). The non-parametric Kruskal Wallis variance analysis was used to determine any differences in the studied parameters among groups, and Mann-Whitney $U$ test was used to find out the source of difference in cases where a significant difference was noted among the groups. $P$ value less than 0.05 was considered statistically significant.

\section{RESULTS}

All 20 rats survived the time to the study start date and the surgical procedure. The groups were analyzed both macroscopically and microscopically. Using the findings of these analyses, the rats were further analyzed for the length of adhesion, intensity of adhesion score, pleural thickness, mesothelial cell proliferation score, MIC infiltration score and macrophage infiltration score.

Mean length of adhesion in Group A and B were $3.0 \pm 2.2$ and $10.0 \pm 2.0$, respectively, while it was $0.0 \mathrm{~cm}$ in Group C. Mean intensity of adhesion scores in the
Group A, Group B, and Group C were 1.5 $\pm 1.0,3.4 \pm 0.7$, and 1.0 \pm 0.0 , respectively (Table 1 ).

Table 1: Comparative lengths and intensities of adhesion among Groups A, B and C

\begin{tabular}{|c|c|c|c|}
\hline \multicolumn{2}{|c|}{ Number of rats } & \multirow{2}{*}{$\begin{array}{c}\begin{array}{c}\text { Length of adhesion } \\
\text { (mm) }\end{array} \\
3\end{array}$} & \multirow{2}{*}{$\begin{array}{c}\begin{array}{c}\text { Intensity of } \\
\text { adhesion score* }\end{array} \\
2\end{array}$} \\
\hline Group A & 1 & & \\
\hline & 2 & 5 & 2 \\
\hline & 3 & 0 & 0 \\
\hline & 4 & 4 & 2 \\
\hline \multirow{8}{*}{$\underset{(n=8)}{\text { Group B }}$} & 1 & 9 & 4 \\
\hline & 2 & 8 & 4 \\
\hline & 3 & 9 & 2 \\
\hline & 4 & 11 & 3 \\
\hline & 5 & 10 & 4 \\
\hline & 6 & 11 & 4 \\
\hline & 7 & 14 & 3 \\
\hline & 8 & 8 & 3 \\
\hline \multirow{8}{*}{$\underset{(n=8)}{\text { Group C }}$} & 1 & 0 & 1 \\
\hline & 2 & 0 & 1 \\
\hline & 3 & 0 & 1 \\
\hline & 4 & 0 & 1 \\
\hline & 5 & 0 & 1 \\
\hline & 6 & 0 & 1 \\
\hline & 7 & 0 & 1 \\
\hline & 8 & 0 & 1 \\
\hline
\end{tabular}

*1: No adhesion, 2: Loose: Which can be removed with blunt dissection, 3: Moderate: Some of which requires sharp dissection, 4: Severe: All of which requires sharp dissection.

Mean pleural thickness values were $306.3 \pm$ $199.4,357.5 \pm 289.2$ and $226.3 \pm 141.8$ for Group A, Group B, and Group C, respectively (Table 2). The three groups did not differ significantly in terms of pleural thickness $(P>0.05)$.

Mean mesothelial cell proliferation scores were $1.1 \pm 0.3,2.7 \pm 1.2$, and 1.6 \pm 0.4 in Group A, Group B, and Group C, respectively (Table 3), and statistically significant difference was identified between the Group A and Group $C(P<0.05)$. Mesothelial cell proliferation was reduced in the Group B while mesothelial cell proliferation could reach to certain level in the Group A and Group C.

Mean MIC infiltration score was $1.3 \pm 0.4,1.7 \pm 0.7$, and 1.3 \pm 0.3 for Group A, Group B, and Group C, respectively. Mean macrophage infiltration score was $1.3 \pm 0.3,1.5 \pm 0.3$, and $1.4 \pm 0.5$ for Group A, Group B, and Group C, respectively (Table 3). No statistically significant difference was noted among the groups for these two parameters $(P>0.05)$ (Table 4$)$. 
Table 2: Measurements of pleural thickness where adhesions were most intense in Groups A, B and C

\begin{tabular}{ccc}
\hline \multicolumn{2}{c}{ Number of rats } & Pleural thickness $(\mu \mathrm{m})$ \\
\hline$\underset{(\mathbf{n}=4)}{\text { Group }} \mathbf{4}$ & 1 & $350-200$ \\
& 2 & $50-50$ \\
& 3 & $500-250$ \\
Group $_{(\mathbf{n}=\mathbf{8})}$ & 4 & $700-350$ \\
& 1 & $200-180$ \\
& 2 & $150-280$ \\
& 3 & $200-150$ \\
& 4 & $350-120$ \\
& 5 & $550-120$ \\
& 6 & $1300-800$ \\
Group C & 7 & $350-140$ \\
& 8 & $380-400$ \\
& 1 & $430-350$ \\
& 2 & $550-280$ \\
& 3 & $100-50$ \\
& 4 & $150-600$ \\
& 5 & $150-100$ \\
& 6 & $450-300$ \\
& 7 & $50-250$ \\
& 8 & $800-650$ \\
\hline
\end{tabular}

Table 3: Measurements of mesothelial proliferation, mononuclear cell infiltration and macrophage infiltration where adhesions were most intense in Groups A, B and $\mathrm{C}$

\begin{tabular}{|c|c|c|c|c|}
\hline \multicolumn{2}{|c|}{$\begin{array}{l}\text { Number of } \\
\text { rats }\end{array}$} & $\begin{array}{l}\text { Mesothelial } \\
\text { proliferation } \\
\text { score* }\end{array}$ & $\begin{array}{l}\text { MIC infiltration } \\
\text { score }^{* *}\end{array}$ & $\begin{array}{l}\text { Macrophage } \\
\text { infiltration } \\
\text { score }^{* * *}\end{array}$ \\
\hline \multirow{4}{*}{$\underset{(n=4)}{\text { Group } A}$} & 1 & 1111 & 1211 & 1221 \\
\hline & 2 & 1111 & 1111 & 1111 \\
\hline & 3 & 1111 & 1111 & 1111 \\
\hline & 4 & 1221 & 1231 & 1221 \\
\hline \multirow{8}{*}{$\underset{(n=8)}{\operatorname{Group}} B$} & 1 & 1243 & 1111 & 1211 \\
\hline & 2 & 1111 & 3333 & 2112 \\
\hline & 3 & 1111 & 1211 & 1211 \\
\hline & 4 & 1441 & 1211 & 2212 \\
\hline & 5 & 4444 & 2211 & 2311 \\
\hline & 6 & 4444 & 1221 & 1221 \\
\hline & 7 & 2442 & 2221 & 1111 \\
\hline & 8 & 4333 & 3321 & 2312 \\
\hline \multirow{8}{*}{$\underset{(n=8)}{\operatorname{Group}} \mathrm{C}$} & 1 & 1211 & 1111 & 1111 \\
\hline & 2 & 1211 & 1211 & 1111 \\
\hline & 3 & 1211 & 1111 & 1111 \\
\hline & 4 & 1131 & 1211 & 1211 \\
\hline & 5 & 1122 & 1121 & 1121 \\
\hline & 6 & 2331 & 2221 & 2331 \\
\hline & 7 & 1331 & 1221 & 1331 \\
\hline & 8 & 1322 & 1112 & 2122 \\
\hline
\end{tabular}

*1: Pleural surface is completely covered with mesothelium cells, 2 : Fifty percent of pleural surface is covered with mesothelium cells, 3 : Less than $50 \%$ of the pleural surface is covered with mesothelium cells, 4: Absence of mesothelium tissue.
**1: Mild: Almost no MIC, 2: Moderate: MIC count < 100, 3: Marked: MIC count $>100$

***1: Mild: Almost no macrophages, 2: Moderate: Macrophage count <100, 3: Marked: Macrophage count $>100$.

Statistically significant differences were found among all three groups in terms of mean length of adhesion. For mean intensity of adhesion, on the other hand, significant differences were noted between the Group A and Group B and between the Group B and Group $C(P<0.05)($ Table 4,5$)$. These findings showed macroscopic adhesions in the Group A and Group B, while adhesion was not noted in any of the rats in the Group C.

Table 4: Statistical comparison of Group A, Group B and Group $C$ by mean adhesion length, mean adhesion score, mean mesothelial proliferation score, mean pleural thickness, mean mononuclear cell infiltration score and mean macrophage infiltration score

\begin{tabular}{ccccc}
\hline & Group A & Group B & Group C & $\boldsymbol{P}$ \\
\hline $\begin{array}{c}\text { Length of adhesion } \\
\text { (Mean } \pm \text { SD) }\end{array}$ & $3.0 \pm 2.2$ & $10.0 \pm 2.0$ & $0.0 \pm 0.0$ & $0.000^{*}$ \\
$\begin{array}{c}\text { Adhesion score } \\
\text { (Mean } \pm \text { SD) }\end{array}$ & $1.5 \pm 1.0$ & $3.4 \pm 0.7$ & $1.0 \pm 0.0$ & $0.001^{*}$ \\
$\begin{array}{c}\text { Mesothelial pro- } \\
\text { liferation score } \\
\text { (Mean } \pm \text { SD) }\end{array}$ & $1.1 \pm 0.3$ & $2.7 \pm 1.2$ & $1.6 \pm 0.4$ & $0.037^{*}$ \\
$\begin{array}{c}\text { Pleural thickness } \\
\text { (Mean } \pm \text { SD) } \\
\text { MIC infiltration }\end{array}$ & $306.3 \pm$ & $357.5 \pm$ & $226.3 \pm$ & 0.534 \\
$\begin{array}{c}\text { score } \\
\text { (Mean } \pm \text { SD) }\end{array}$ & $1.3 \pm 0.4$ & $1.7 \pm 0.7$ & $1.3 \pm 0.3$ & 0.321 \\
$\begin{array}{c}\text { Macrophage infil- } \\
\text { tration score (Mean } \\
\quad \pm \text { SD) }\end{array}$ & $1.3 \pm 0.3$ & $1.5 \pm 0.3$ & $1.4 \pm 0.5$ & 0.522 \\
\hline
\end{tabular}

Table 5: Statistical comparisons between Group A-Group B, Group A-Group C and Group B-Group C

\begin{tabular}{cccc}
\hline & $\begin{array}{c}\text { Group } \\
\text { A-Group B }\end{array}$ & $\begin{array}{c}\text { Group } \\
\text { A-Group C }\end{array}$ & $\begin{array}{c}\text { Group } \\
\text { B-Group C }\end{array}$ \\
\hline $\begin{array}{c}\text { Mean adhesion } \\
\text { length }\end{array}$ & $\mathrm{p}=0.006$ & $\mathrm{p}=0.007$ & $\mathrm{p}=0.00$ \\
$\begin{array}{c}\text { Mean adhesion } \\
\text { intensity score }\end{array}$ & $\mathrm{p}=0.01$ & $\mathrm{p}=0.102$ & $\mathrm{p}=0.00$ \\
$\begin{array}{c}\text { Mean mesothelial } \\
\text { proliferation score }\end{array}$ & $\mathrm{p}=0.052$ & $\mathrm{p}=0.037$ & $\mathrm{p}=0.091$ \\
\hline
\end{tabular}




\section{DISCUSSION}

This study of an experimental intrapleural adesion model revealed three points: (a) The anti-adhesion effects of Prevadh ${ }^{\circledR}$ was achieved following thoracotomy, and length of adhesion and intensity of adhesion scores revealed better results in Group C. (b) The mesothelial cell proliferation scores were increased in the Group C. (c) Prevadh ${ }^{\circledR}$ did not affect the mean pleural thickness values, mean MIC infiltration score and mean macrophage infiltration score.

Problems during mesothelial layer repair secondary to tissue damage at the serosal cavities may result in adhesion. Abdomen is the body part where post-operational adhesions are observed, and requires emergency repeat surgery most commonly. Adhesions are reported as a sequel in $90 \%$ of laparotomies [2]. These adhesions lead to increased morbidity and mortality and results in significant financial losses. In 1998, 1.2 billion dollars were spent to cure abdominal adhesions just in the USA $[8,9]$. Therefore, the majority of studies on prevention of adhesions were conducted by professionals involved in abdominal surgeries. There are only a few clinical and experimental studies that looked into the prevention of adhesion in thoracic surgery. Besides, the increasing numbers of recurrent thoracotomy cases and serious complications that develop during and following surgical interventions of these patients have led us to conduct this study [10-12].

Witnessing the issues with recurrent thoracotomies, Tanaka et al. demonstrated that adhesions which develop following thoracotomies may be successfully eliminated using hyaluronate-based absorbable membran in rats [6]. Getman et al. observed no adhesions in patients who were administered TachoSil ${ }^{\circledR}$ for bleeding control and air leaks when the authors performed recurrent thoracotomy for any reason, and confirmed the efficacy of TachoSil ${ }^{\circledR}$ as an anti-adhesive agent by performing an experimental rat study [7]. In addition, Ginsburg et al., in two cases who they performed two-stage anterior spinal procedure for correction for severe kyphosis, placed silicone rubber over the vertebra following the first surgery and observed in the second thoracotomy that there was no adhesion between the lung and vertebra [13].

In the present study, the Group B containing rats with induced adhesion had longer and more intense adhesions compared to the Group A, which only underwent thoracotomy, demonstrating the efficacy of the applied adhesion model. On the other hand, in the Group C, which included rats with induced adhesion and received Prevadh $\AA$, no adhesion developed across the thoracotomy line in any of the rats. An assessment of adhesion length and adhesion score yielded significantly lower scores for the Group C. In other words, use of Prevadh ${ }^{\circledR}$ prevents adhesion at the administration site with a $100 \%$ efficacy. No inconvenience associated with Prevadh ${ }^{\circledR}$ administration was experienced throughout the study. It is possible to achieve firm grasp by wetting the intact surface with saline solution or by applying directly on the bleeding surface. This excludes a possible displacement from the application zone. This may have a further potential advantage in that it may prevent air leaks in lung surgeries. However, it should be demonstrated in an experimental study.

In addition to confirming anti-adhesion agents' clinical benefits, risk-benefit ratio associated with use of these agents should also be established before they may find routine use in surgical settings, since use of these state-of-art and expensive products will present an additional, significant financial burden on both the patient and payers. On the other hand, increasing number of patients requiring recurrent thoracotomy and complications that develop during interventions to eliminate adhesions makes it necessary to use anti-adhesion agents in selected patients in the thoracic surgeries. What is important here is to develop well-established criteria to determine these selected patients, and the indications for use of anti-adhesion agents in thoracic surgery. Currently, no relevant data is available in the literature. We believe that these agents should be administered to all patients who underwent thoracotomy during the early phase of life, those for whom two-stage lung or thoracic wall surgery is planned and in cases of metastatic cancers of the lungs where there is a high risk for recurrent surgery. These agents may also be recommended for patients with low respiratory reserve or those prone to bleeding in order to prevent possible air leaks and bleeding complications that may result from recurrent thoracotomy.

Another important question is how to choose the correct anti-adhesion agent. An ideal anti-adhesion agent should not hinder wound-healing, not predispose the patient to infection, prevent fibrosis, maintain its presence in the tissue throughout the natural healing process, and not cause foreign matter reaction. Also, it should be easily eliminated from the body after healing, and should also be usable for thoracoscopic surgeries. In addition, anti-adhesion agents which can prevent bleeding and air leaks often observed following lung resections are expected to be more advantageous in the thoracic surgery. 
Limitations of this study include the low number of rats and the lack of use of various anti-adhesion agents. Our findings are also based on the result of macroscopic and histopathological examinations. However, biochemical data would elucidate physiopathological changes associated with pleural adhesion and the effects of Prevadh ${ }^{\circledR}$. Experiments involving a higher number of rats especially in Group $\mathrm{A}$, and different anti-adhesion agents may yield more comprehensive results.

\section{CONCLUSION}

The present study demonstrated in a rat model that Prevadh ${ }^{\circledR}$ was an efficient anti-adhesion agent. We believe that using Prevadh ${ }^{\circledR}$ in the presence of right indications will reduce adhesions following thoracotomy. However, as in any experimental study, this conclusion should be supported by clinical trials.

\section{Conflict of Interest}

The authors have declared that no conflict of interest exists.

\section{References}

1. Strange C, Baumann MH, Sahn SA, Idell S. Effects of intrapleural heparin or urokinase on the extent of tetracycline-induced pleural disease. Am J Respir Crit Care Med 1995;151:508-15.

2. Burns JW, Colt MJ, Burgess LS, Skinner KC. Preclinical evaluation of Seprafilm bioresorbable membrane. Eur J Surg Suppl 1997:577:40-8.

3. Baulieux J, Arnaud JP, Berdah S, Champault G, Chipponi J, Desrousseaux B, Domergue J, Delattre JF, Fagniez PL, Favre JP, Fourtanier G, Gouillat C, Mantion G. Prevention of adhesions in digestive surgery using the Prevadh kit. Indications, work up and experience. Ann Chir 2004;129:9-12.

4. Jaklitsch MT, Mery CM, Lukanich JM, Richards WG, Bueno R, Swanson SJ, Mentzer SJ, Davis BD, Allred EN, Sugarbaker DJ. Sequential thoracic metastasectomy prolongs survival by re-establishing local control within the chest. J Thorac Cardiovasc Surg 2001;121:657-67.

5. Onen A, Sanli A. Surgical treatment of synchronous and metachronous lung cancer. Tur Toraks Der 2004;5:201-7.

6. Tanaka A, Abe T, Matsuura A. Prevention of postoperative intrapleural adhesion of the thoracotomy incision by a bioresorbable membrane in the rat adhesion model. Ann Thorac Cardiovasc Surg 2000;6:151-60.

7. Getman V, Devyatko E, Wolner E, Aharinejad S, Mueller MR. Fleece bound sealing prevents pleural adhesions. Interact Cardiovasc Thorac Surg. 2006;5: 243-6.

8. Ray NF, Larsen JWJr, Stillman RJ, Jacobs RJ. Economic impact of hospitalizations for lower abdominal adhesiolysis in the United States in 1988. Surg Gynecol Obstet. 1993;176:271-6.

9. Wilde R. The need for adhesion reduction. Future Directions. In Surgery. 2006; 27-30.

10. Tutic M, Lardinois D, Imfeld S, Korom S, Boehler A, Speich R, Bloch KE, Russi EW, Weder W. Lung-volume reduction surgery as an alternative or bridging procedure to lung transplantation. Ann Thorac Surg. 2006;82:208-13.

11. Wisser W, Deviatko E, Kupilik NS, Senbaklavaci Ö, Huber ER, Wolner E, Klepetko W. Lung transplantation following lung volume reduction surgery. J Heart Lung Transplant 2000;19:480-7.

12. Shitrit D, Fink G, Sahar G, Eidelman L, Saute M, Kramer MR. Successful lung transplantation following lung volume reduction surgery. Thorac Cardiovasc Surg 2003;5:274-6.

13. Ginsburg GM, Mahour GH, Bassett GS. Use of a siliconized nylon sheet to prevent pleural adhesions during staged thoracotomy procedures for kyphosis. Orthopedics 2000;23:1253-5. 